\section{The aggression of male mice against androgenized females}

\author{
ROGER A. MUGFORD and NORMAN W. NOWELL \\ University of Hull, Yorkshire, England
}

Two matched groups of 24 isolated male mice were aggression tested against spayed, daily-injected females. One group of females received testosterone propionate, and a control group a placebo. The TP-treated females were attacked significantly more than were the controls after 5-9 injection days. This delay indicates that the females' aggression-eliciting cue may be in the form of a pheromonal substance released from an androgen-dependent tissue, rather than being an excreted androgen metabolite.

While males of most laboratory mouse strains will attack and injure other males, they are only rarely aggressive toward females (Scott \& Fredericson, 1951). Attacks against females are only of short duration, so that a strange heterosexual pair soon coexist peacefully. By contrast, two strange males rapidly establish a dominance order, and the subordinate mouse may suffer continued injury if it cannot escape. We have been interested in identifying the mechanisms that afford female mice this protection from male aggression.

In a recent study, we found that administration of testosterone propionate (TP) to both intact and spayed female mice, greatly increased the severity of attacks from isolated, aggressive males. The effect of male hormone was greater in the latter group. The present study investigates the time relations between daily injections of TP and the onset of this aggression-facilitative effect in spayed fernale mice.

\section{METHOD}

The animals used were taken from a randomly bred albino mouse colony maintained by the University of Hull Zoology Department.

Forty-eight males were isolated when weaned at 21 days, and were 60 days old when used as fighter mice against 48 female opponents. The latter had been housed in groups of six since weaning and were bilaterally ovariectomized when 180 days old. Two weeks after the operation, each female was coded with picric acic fur dye and then used as a regular opponent against a test fighter mouse. Aggression testing took place in the $11 \times 8 \times 4$ in. Makrolon home cage of the fighter. The wire mesh cover and sawdust were changed before each test.

The aggressiveness of the fighter mouse against its female opponent was assessed by

*The authors are grateful to Angela Wouters for her help with injecting the animals and to $G$. Lowe for his advice and criticism.
(1) the latency up to the first bite and (2) the total number of bites delivered in a 4-min observation period. The tests were performed daily and at the same time for each pair of mice.

After the third day of testing, the fighter mice were matched on the biting score, and assigned to an experimental (A) or a control (B) group of 24 animals. Before testing on the fourth and successive days, the appropriate female opponents of the Group A fighters received an intramuscular injection of 100 micrograms TP in $0.1 \mathrm{ml}$ of arachis oil. Opponents of Group B fighters were injected with an oil placebo.

On the 12th and last day of testing, a crossover design was adopted, so that Group B fighters were paired against TP-injected females, and Group A fighters against placebo-injected females.

RESULTS AND DISCUSSION

The effect of TP was not exerted until

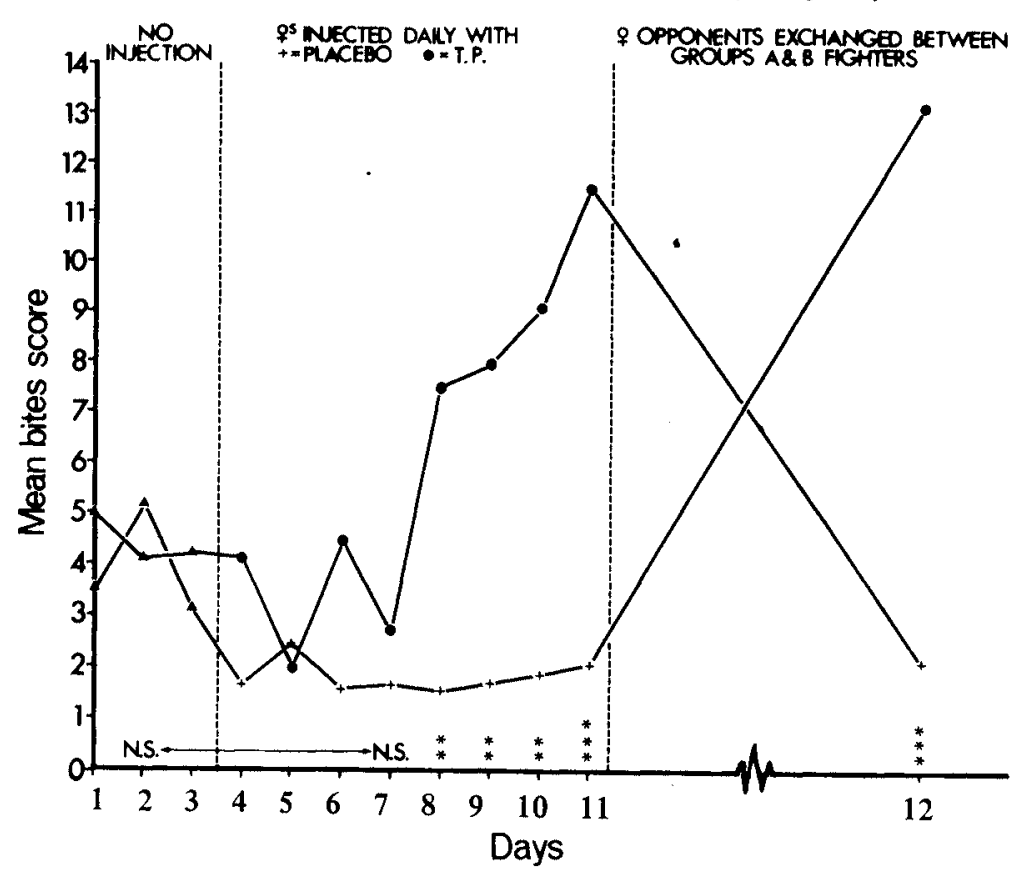

Fig. 1. Mean biting scores. P values are derived from a Mann-Whitney U-test. $*=.05$, $* *=.01, * * *=.001$, n.s. $=$ not significant showed that skin sebum production in spayed female rats is increased by $T P$ administration, and the same authors note that such sebum has odorous qualities. Mugford \& Nowell (in press) have also recently suggested the involvement of a specialized sebaceous gland, the preputial, as the source of a TP-induced urinary mice.

The increased aggression scores of the Group A fighters were entirely a function of changing aggression-eliciting stimuli from the female opponents, rather than any characteristic of the male fighters. Thus, a comparison on all measures for Days 11 and 12 shows that the crossover procedure reduced Group A's scores to the level previously occupied by Group B (Figs. 1 to 3). Similarly, the aggressiveness of Group B fighters paired with TP-injected females on Day 12 greatly increased so as the fifth injection day, after which the bites score rose steeply and latencies shortened (Figs. 1 to 3). This delayed action may indicate that the aggression-permissive cues stimulated in the experimental females were not the direct result of TP or its excreted metabolites, but involved some other intermediate process. Since there were no obvious behavioral changes in the TP-treated females (other than those that were a consequence of severe defeat), it seems likely that androgen-controlled secretory mechanisms may have produced changed odor cues in these females. In this connection, Strauss \& Ebling (1970) aggression-promoting pheromone in female

Psychon. Sci., 1970, Vol. 20 (3) 


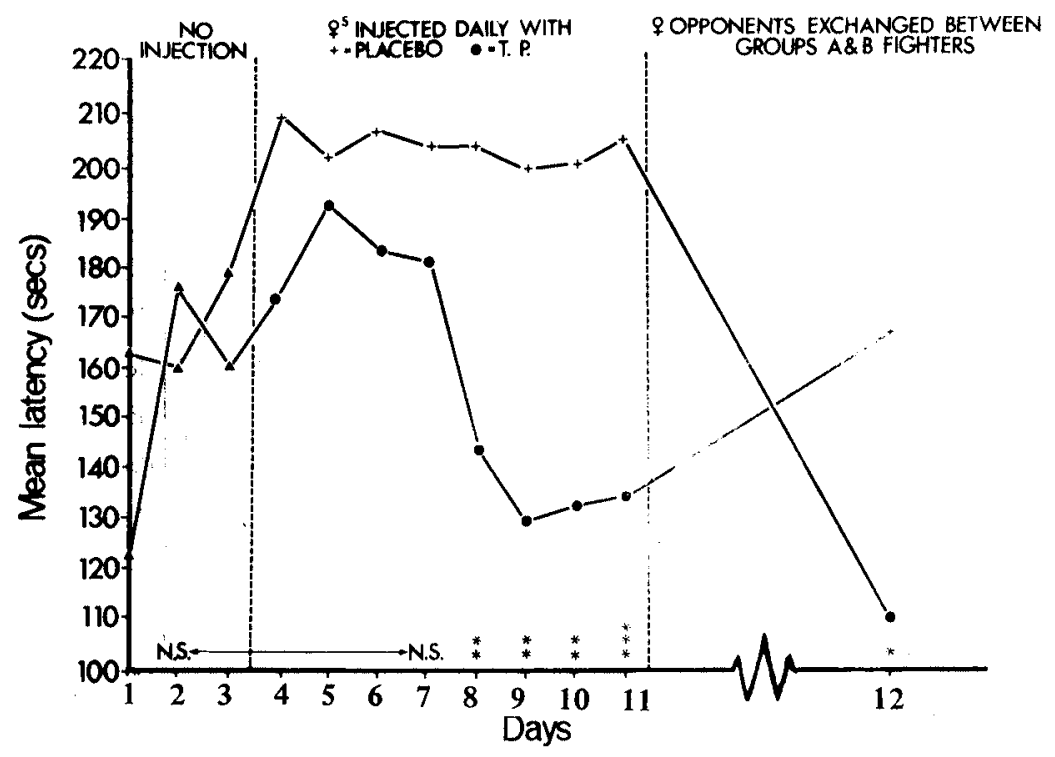

Fig. 2. Mean latencies to the first bite. P values derived from a Mann-Whitney U-test.

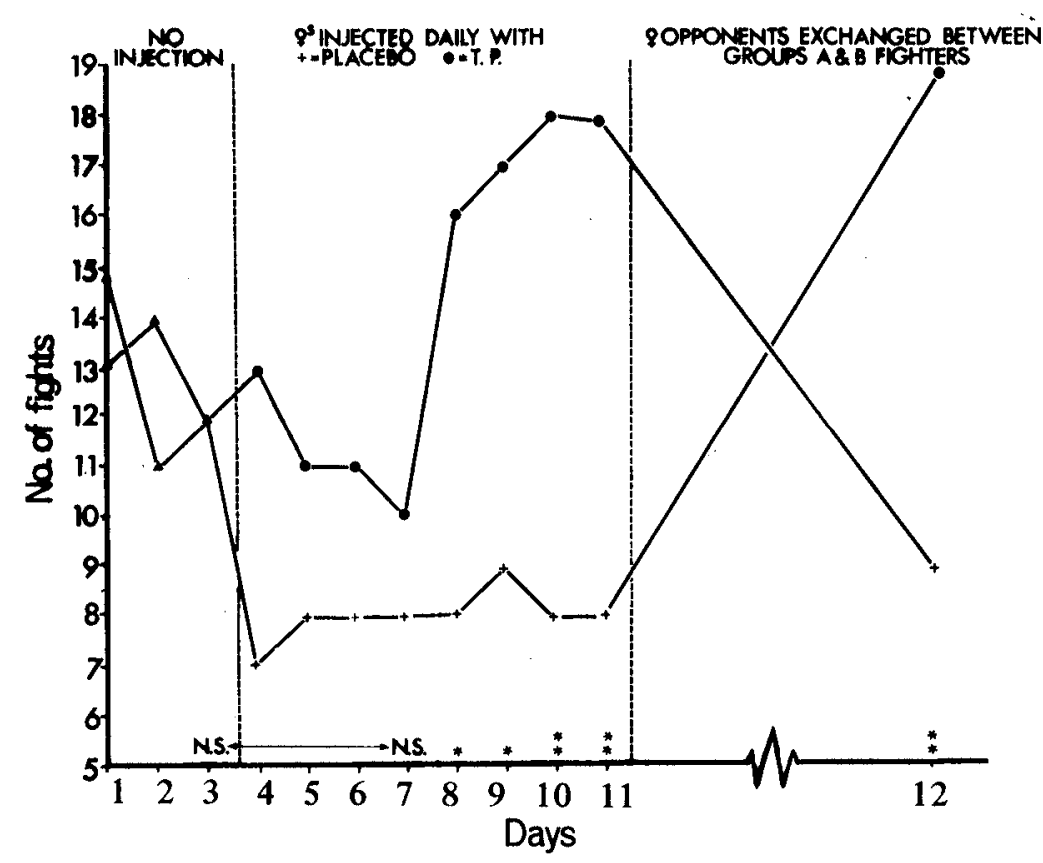

Fig. 3. Number of fights. $P$ values derived from a chi-square test $(N=24)$.
Table 1

Aggression Scores for Test Days 11 and 12 Combined $(N=48)$

\begin{tabular}{|c|c|c|c|}
\hline $\begin{array}{l}\text { Aggression } \\
\text { Measure }\end{array}$ & $\begin{array}{c}\text { TP. } \\
\text { Injected } \\
\text { Opponents }\end{array}$ & $\begin{array}{l}\text { il-Injected } \\
\text { Control } \\
\text { Oppo- } \\
\text { nents }\end{array}$ & $P$ Values \\
\hline Latency & 122 & 187 & $.00023^{*}$ \\
\hline $\begin{array}{l}\text { Number } \\
\text { of Bites }\end{array}$ & 12.4 & 2.4 & $.00003^{*}$ \\
\hline $\begin{array}{l}\text { Number of } \\
\text { Fights of a } \\
\text { Possible } 48\end{array}$ & 37 & 17 & $.0004 t$ \\
\hline
\end{tabular}

*Wilcoxon-matched pairs signed-ranks test. †Fishers's exact probability test.

to slightly exceed the Day 11 scores of Group A fighters against their opponents.

Table 1 shows that the fighter mice were significantly more aggressive toward females injected with TP for a period of 8 to 9 days than toward oil-injected controls. It would therefore seem that not only is male aggression itself androgen mediated (Bevan, Daves, \& Levy, 1960), but also the pheromonal cues that elicit this behavior depend upon this hormone. Thus, female mice do not exhibit spontaneous aggressive behavior. They do in fact, as Mugford \& Nowell (1970) have previously shown, inhibit severe attack from proximal males via a urinary pheromone. However, treatment with male hormone removes this protection, which in the normal female must be essential for her successful reproductive role.

\section{REFERENCES}

BEVAN, W., DAVES, W. F., \& LEVY, G. W. The relation of castration, androgen therapy, and pre-test fighting experience to competitive aggression in C57 BL/10 mice. Animal Behavior, 1960, 8, 6-10.

MUGFORD, R. A., \& NOWELL, N. W. Endocrine control over production and activity of the anti-aggression pheromone from female mice. Journal of Endocrinology, in press.

MUGFORD, R. A., \& NOWELL, N. W. Pheromones and their effect on aggression in mice. Nature, 1970, 226, 967-968.

SCOTT, J. P., \& FREDERICSON, E. The causes of fighting in mice and rats. Physiological Zoology, 1951, 24, 273-309.

STRAUSS, J. S., \& EBLING, F. J. Control and function of skin glands in mammals. In G. K. Benson \& J. G. Phillips (Eds.), Hormones and the environment: Memoirs of the Society for Endocrinology. Vol. 18. Cambridge: Cambridge University Press, 1970. Pp. 341-371. 